\title{
The perception of languages by Italian native speakers*
}

\begin{abstract}
This essay showcases the results of a survey conducted on a sample of Italian speakers which focused on their perception of languages. The research, carried out in the second half of 2019, has enabled corroborating the initial hypothesis about the existence of preconceptions and stereotypes associated with the perception of foreign languages and cultures (Elman \& McClelland 1986) by Italian people. In particular, a questionnaire was used to clarify which adjectives are commonly associated with selected foreign languages, in order to identify certain trends and stereotypes. The survey is based on ethnolinguistic and language education studies (Cardona 2006), and was performed through data collection techniques used in ethnography and sociolinguistics (Tagliamonte 2006).
\end{abstract}

KeYwords: Language education, language perception, ethnolinguistics, educational linguistics, language and culture.

\section{INTRODUCTION}

This perception-based work is aimed at gaining insight into an ethnolinguistic issue, which has not yet been the subject of academic study: the perception of selected languages by Italian native speakers. The fact of the matter is that "the cultural aspect of language usage has been the most overlooked in linguistics" (Cardona 2006: 4).

Our analysis is focused on a sample of individuals with different sociocultural characteristics (gender, age, occupation, education level). The survey was performed by means of a sociolinguistic questionnaire (Nitti 2018b), with the purpose of assessing the survey respondents' perception of languages, as well as the existence of possible historical-cultural preconceptions (Wierzbicka 1999).

* This is a two-author paper, it has been conceived by the two authors together. Giulio Facchetti wrote the abstract together with Section 3. Paolo Nitti wrote Sections 1, 2, 4, 5, 6 and 7. 
The choice of the questionnaire has been, to some extent, problematic, as "the infinite complexity of linguistic phenomena cannot be the object of research; yet, researchers can attempt bringing out some fragments of reality, and therefore of linguistic data, in order to make them the subjects of their questions" (Nitti 2020: 128). The complexity of the linguistic data gathered by means of questionnaires is, in fact, an issue that is well-known and documented in scientific literature: the "data, collected by means of surveys in which speakers are asked to report on how they behave linguistically in given situations [...] require a certain degree of caution, as they are derived from self-declarations" (Berruto 2020: 23). However, the items in our questionnaire enabled us to examining value judgments, stereotypes and personal interpretations held by the respondents (Berruto 2015), regarding each of the considered languages. We offered the participants two options: multiple choice, based on adjectives, and an open field where they could add an extra evaluation (Marello 1999).

The preliminary phase, prior to the data analysis, was devoted to shedding light on the concept of perception, its meaning and on different theories which discuss its relation to the spoken language: "language is the foremost element in the life of any community, the key instrument for facilitating interaction between man and man; it is simply impossible to imagine a social group that does not use at least one language variety in daily exchanges" (Cardona 2006: 3). With the aim of formulating value judgments for the questionnaire, subjective criteria were used, as defined by a pre-questionnaire carried out on a sample of ten speakers, randomly selected.

\section{METHODOLOGICAL PREMISES: THE PERCEPTION OF LANGUAGES}

Perception is a complex process. It enables attributing a meaning to the sensations coming from the real world. The disciplines which deal with perception are traditionally associated with psychology, with the medical and health-related fields and with philosophy. Furthermore, interest in perception has been manifested also by linguists, with particular regard to semantic studies (Volli 2003). This is an extremely interesting and challenging topic, because our perceptions are a representation of what happens in reality, and are a direct source from which the working of the human brain can be investigated (Bazzanella 2019).

In scientific literature, the most important theories regarding perception are:

a) the Empiricist theory, put forward by Hermann von Helmholtz (De Kock 2014), according to which the perception of objects / phenomena surrounding us takes place through experience and learning, which, in turn, derive from the contact we have with the outside world. The sensations 
transmitted to the brain, therefore, represent our total acquired knowledge (after Turner 1994);

b) the Gestalt theory, which holds that the meaning of perceptions depends essentially on the organization of the perceived phenomena. Thus, the stimuli are represented by a number of elements which lead to their organization in a subjective fashion, to the point of developing a context based on personal feelings and perceptions. Such phenomena then enable us to fully perceive all the elements surrounding us (Kanizsa 1980);

c) the New Look theory, the elaboration of which is based on the fact that perception stems from the confrontation between an individual's personal expectations and the surrounding world. In this way, everyone builds their own perception of a particular event or object (Cooper \& Fazio 1984);

d) Neisser's theory, which revolves around the effects which thought patterns exert on attention, which, in turn, allows us to explore the environment surrounding us (Neisser 1993). The individual, in fact, receives information coming from the outside, and highlights the most important features of the objects in order to achieve specific, personal goals.

The above mentioned theories clearly show that what is perceived needs to be organized in such a way as to allow the brain to process and manage all the information, according to the context surrounding the individual (Nitti 2019). Moreover, the presence of a particular object, especially if it represents something new for the mind, triggers another process which requires conscious attention (Burani \& Laudanna 1993). This, in turn, determines the elements that the human brain is able to select, by means of the "focusing and excluding" mechanisms. Applying these concepts to our research, we wish to point out that the perception of languages may be regarded as a result of several mental processes: "these combinations of acoustic and articulatory patterns are based on the physics of sound generation in the vocal tract, including theories of coupled resonators, the influence of vocal-tract walls on sound generation, and discontinuities or stabilities in the behavior of sound sources" (Stevens 2002: 1872). There are a number of sensations, stimuli, expectations, social and cultural premises, and personal experiences, based on which individuals, more or less unconsciously, are able to put forth their own interpretation or judgment about any given language (Nitti 2018a). Furthermore, an individual's personal considerations, together with the perception of the information they received, result in different points of view.

In the Italian context, research on the perception of languages, unfortunately, is limited and lacking in both descriptive and exploratory terms. This contribution, therefore, aims to explore the perception of languages by Italian speakers, in order to recognize tendencies and identify the main implications for general language teaching. This aim was achieved by means of a questionnaire study. 


\section{GLOBALIZATION AND LANGUAGE: ANALYSIS AND CONSEQUENCES}

Globalization is a process which has radically changed our society over the past few decades, with a predominant focus on the Western culture (Tolbert 2001). This phenomenon, as documented in scientific literature, may lead to the weakening of local communities and, in turn, to the possible lack of integration between them. Analyzing the concept of globalization in more depth, however, it is possible to identify an opposing trend, represented by the blossoming of interculturality (Dervin, Gajardo \& Lavanchy 2012). Linguistic contact is par excellence one of the most striking phenomena of interculturality (Dietz 2009). If language is something that has always highlighted the differences between various peoples and cultures, it is equally true that it has represented the "glue" that has kept several communities together (Vedovelli 2003). Furthermore, from a more pragmatic perspective, language has always been, and continues to remain, a key element of communication between people, capable of creating and shaping a common vision of the world (Blommaert 2012). It should also be considered that languages are not spread evenly across the globe and it is often possible to notice striking differences in their distribution worldwide. This is attested to by the fact that only ten languages are widely spread across the world and no more than fifty are spoken by at least five million people (Ostler 2005).

The English language has acquired a significant role, particularly from the economic, scientific and social points of view, and nowadays it is considered to be the world's lingua franca (Seidlholfer 2011). Considering, for example, today's work environment, it is worth highlighting that all companies and businesses, as well as training agencies, consider the knowledge of English a basic requirement for employees and job seekers (De Martino \& Maraschio 2013). In addition to the spread of English as a lingua franca, well documented in scientific literature (Hynninen 2011), we need to take into account aspects such as the vitality of native languages, the ways in which people come into contact with one another, as well as other socio-ethnolinguistic factors (Björkman 2011). These are based on the peoples' cultural history, and lead to the activation of prestige mechanisms, which can be unveiled mainly due to their most common effects: linguistic calques and loans (Cardona 2006).

Another factor which is closely connected with globalization is the steady development and progress of new technologies, the Internet and social media. Such advancements have undoubtedly affected and revolutionized the way people live, think and speak (Hudson 1996). With regard to the nature of this contribution, it is worth highlighting that technology can accelerate the speed of information transmission and foster cultural and linguistic contacts (Underhill 2012). The spread 
of technology also leads to a more diffuse knowledge of linguistic systems, partly compensating for the cultural preconceptions related to language value judgments.

\section{THE SAMPLE}

The sample subjected to the analysis is composed of survey results offered by 153 native Italian-speakers. They responded to a questionnaire which dealt with their personal perception of different languages (Patel 2008). There were 53\% female respondents and $47 \%$ males in the group. However, in the analysis there is no reference to gender difference in the answers collected. With regard to age, the sample covers relatively young participants. More specifically, $19 \%$ were between 19 and 20, 43\% were between 21 and 40, 34\% between 41 and 60, and 4\% were over 61 years of age ${ }^{1}$. As regards occupation, $36 \%$ were university students, $36 \%$ were primary and middle school teachers, $8 \%$ were freelancers and the remaining $20 \%$ were company employees and clerks. The origin of the sample is not relevant in terms of their differing judgments, but the group comprises residents in the Northern (84\%) and the Southern (26\%) parts of Italy. Particularly worthy of mention is the fact that $75 \%$ of the respondents stated that they knew English, at least at an intermediate level (B1-B2, according to the Common European Framework of Reference for Languages). This seems to be one of the consequences of the above mentioned globalization process. Furthermore, almost $45 \%$ of the participants in the survey claimed to be bilingual, being fluent in another European language in addition to English. There was a meaningful presence (29\%) of Italian dialect speakers, though they represented a minority; $71 \%$ of the respondents claimed to speak only Italian (Telmon 1990). $64 \%$ of the sample had a tertiary education background, while the rest of the informants had a secondary school education background. Their academic fields of specialization were human sciences $(63 \%)$, technology $(22 \%)$, architecture $(6 \%)$, other $(9 \%)$. Each social and cultural difference was used in order to interpret the answers and to establish significant correlations, but few of these data types demonstrated a valid correlation, because of the consistency of stereotypes functioning in the culture (Yule 2020: 311-329).

\section{THE QUESTIONNAIRE}

The analysis of language choices requires, at times, the adoption of specific tools to frame extraordinarily complex phenomena (Loewen \& Plonsky 2016). The closest discipline to which educational linguistics refers in the analysis of linguistic

\footnotetext{
${ }^{1}$ The grouping of age was made up according to sociolinguistic practice (Rapallo 1994).
} 
phenomena is sociolinguistics (Nitti 2020). In general, sociolinguistics deals with the study of the main axes of language variation (Wardhaugh 2006). Language may change depending on space (diatopy), time (diachrony), channel (diamesia), the communicative event (diaphasia), and the social groups involved in the interactional social context (diastratia). These dimensions are not easily separated, to the extent that some theorists have questioned their segmentation, especially with regard to diastratia and diaphasia. The variables, in fact, appear as a very thick network of relationships and characterize discursive and textual practices with respect to communicative events (Garrett 2012). Sociolinguistics, however, in addition to the dimensions of variation, also deals with privileged research methods in linguistics (Berruto 2015), focusing especially on the collection of data, questionnaires, and interviews (Kanizsa 1980). Indeed, the questionnaire, in a narrow sense, is a debt that sociolinguistics itself owes to other social sciences, in particular sociology and ethnology. The linguistic survey, however, deals with the description and classification of linguistic uses in relation to communities or groups of speakers:

a sociolinguistic interview is a particular kind of social occasion: it is a naturally bracketed spate of activity in which particular kinds of actions and behavior are expected [...]. Those expectations provide a framework for Interpreting what is said, e.g., for Interpreting a question as seeking a particular kind of information. Furthermore, the relationship of those expectations to the interpretive processes guiding all social interaction can be made more or less explicit within an utterance. It seems clear that what those being interviewed by a sociolinguist expect (at least initially) is an agenda in which one person (thought of as 'the interviewer') asks questions that they are to answer. Awareness of this agenda provides a dominant frame within which what is said is understood, and specific utterances may display their relevance to this frame (Schiffrin 1993: 249-250).

Generally, regarding language choice surveys, "Sociolinguistic questionnaires are used to analyze interlanguage or the languages of learners and teachers, the perception of language use and the practices for teaching the language" (Nitti 2018b:34).

As with any research-related tool, the questionnaire is dependable on the characteristics of the survey and the phenomena to be studied:

the preliminary, and often most complex, phase of each investigation will have to clarify its objectives and formulate the questions to which it proposes to respond. It is at this moment that the general questions and the articulation of the questions of a more specific nature, which constitute what is commonly called the outline of research, must be explained as clearly and in detail as possible (Nitti 2020: 128).

Since in this contribution our aim is to identify the main stereotypes attributed to modern foreign languages by Italian speakers, the questions which guided our research were: 
- what consideration do Italian individuals have of foreign languages?

- what are the most common adjectives related to how Italian people perceive languages?

- are there any stereotypes associated to the perception of foreign languages for Italian people?

- what is the role of language education in preventing and contrasting these stereotypes?

However, one needs to bear in mind that opinions expressed by our informants are free from problems. Instead,

- the informant can be insincere or not objective in her / his answers;

- the informant can be concerned about the judgment of the researcher;

- the informant does not respond or responds in an irrelevant manner. Beyond the highlighted problems, there is also "a question of setting certain parameters on what can be used as empirical evidence, that is, on what, in the context of that survey, linguistic data is. Whatever the choice made, linguistic data must therefore be sought and produced (rather than simply collected), or more precisely constructed, through a series of procedures that, if necessary, must be declared and made explicit each time" (Nitti 2020: 128).

It was decided to divide the questionnaire into different sections in order to prove aspects related to the perception of foreign languages (Cooper \& Fazio 1984). In order to facilitate the analysis, it was chosen to insert close-ended questions and a space for free notes at the end of each section, so that informants could insert their non-explicit considerations within the pre-established answers (Nitti 2018b). A semi-structured questionnaire would have taken longer to complete and generated a higher difficulty of analysis, caused by the referral of the answers in definite taxonomies, and a higher risk of misinterpretation, during the analysis phase. In fact, a free survey needs more time to process the data because it will be necessary to consider all the answers and index them according to large-scale descriptors (Nitti 2018b).

The questionnaire completion was planned to take place around 15 minutes. A more detailed questionnaire would have implied a longer completion time, with the risk of affecting the validity of the data: "generally speaking, a questionnaire should never be too long, as the informants would tend to produce random and false answers; a range of 20-30 questions seems to be reasonable, as well as the time of 15-20 minutes needed for the compilation" (Nitti 2018b: 36).

As to the content of the research tool itself, its first section, following the title page, is constituted by a set of five questions related to general information, including the level of education, age, profession, and gender of the informant (Neisser 1993). The second section, consisting of 12 questions, focuses specifically on the perception of foreign languages. This part requires the choice of an adjective referring to each language investigated. With respect to the languages surveyed, 
preference was given to those most frequently taught in Italian educational contexts (Vedovelli 2003). In addition, each question includes the "I don't know / I cannot answer" field to avoid the distortion of the answers and allow the informant to express her / his own thoughts without resorting to the proposed labels.

\section{DATA ANALYSIS}

Data processing, as mentioned above, is based on the description and personal perception of language ${ }^{2}$ by a sample composed of Italian native speakers. Our survey shows that the opinions we collected vary from respondent to respondent, according to their gender, age, nationality and other aspects pertaining to their identity. We also wish to highlight that the above reported sociolinguistic factors have proven to be significant and relevant.

Most study paticipants defined the Italian language as musical, lively, sweet, lyrical and artistic. Some subjects, as shown in Pie Chart 1, reported that the Italian language is complicated and difficult. Those who associated this language with the alleged difficulty tend to possess a higher educational level (MA degree $89 \%$, in human sciences $45 \%$, in scientific and technological fields $42 \%$, other $2 \%$ ), while those who opted for the artistic and lyrical aspects of the language hold a lower educational degree (BA degree - 95\%, in human sciences $67 \%$, in scientific and technological fields $22 \%$, other $1 \%$ ).

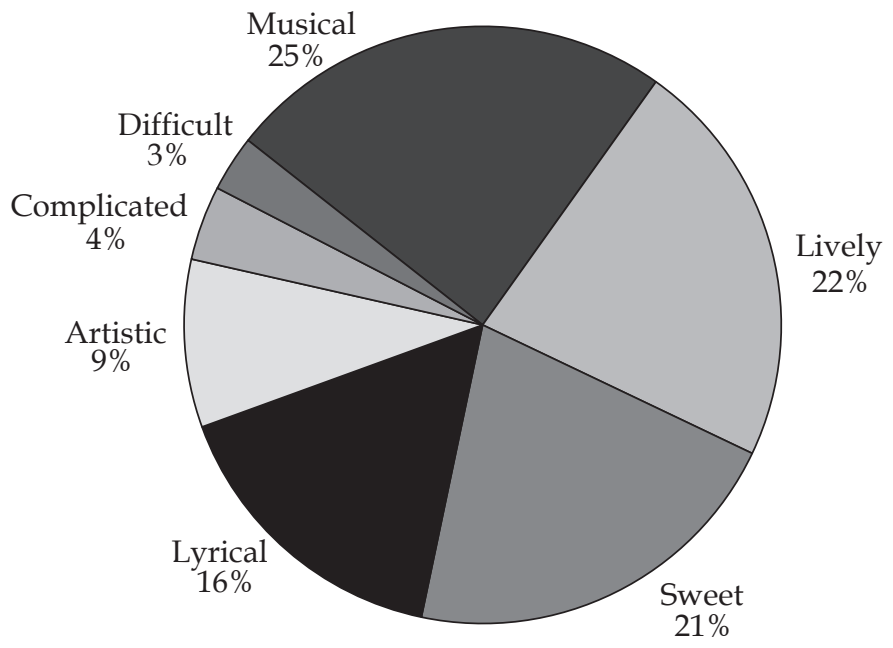

Figure 1. Perception of the Italian language

2 The selected languages, according to the most studied in Italy are Arabic, Chinese, English, French, German, Russian and Spanish, https://ec.europa.eu/italy/news/20170925_insegnamento_lingue_straniere_scuola_primaria_it [access: 20.01.2021]. 
The description of the English language provided by our respondents are fairly homogeneous, regardless of their level of proficiency in English: the majority describe it as being a contemporary, pragmatic and commercial language (85\%). Few of the participants consider English to be a difficult $(7 \%)$, ancient $(6 \%)$ or inexpressive / aseptic (2\%) language. The most plausible interpretation of these results can be made with regard to the role of English as a lingua franca in today's work environment (Hynninen 2011), as mentioned above.

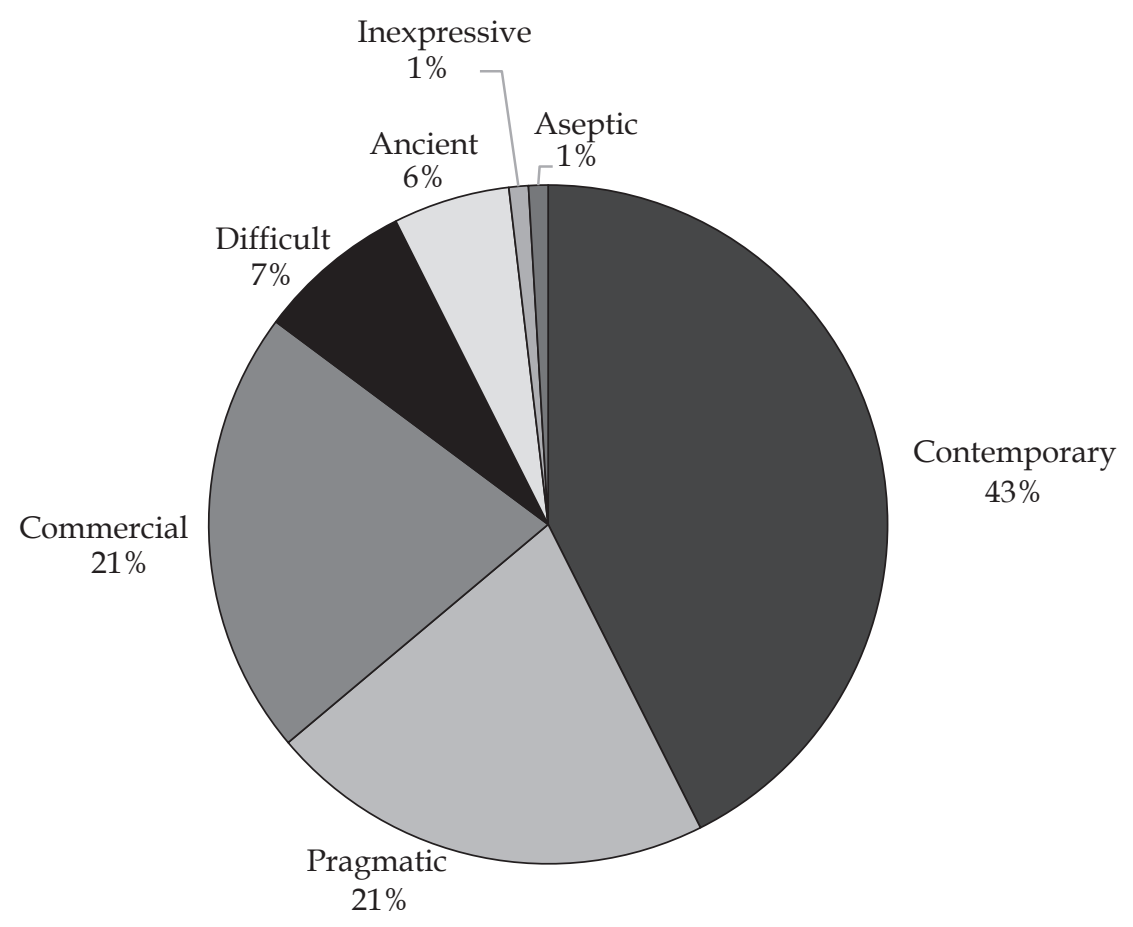

Figure 2. Perception of the English language

The perception of the German language, on the other hand, is remarkably similar among all respondents, regardless of their social or educational status. The participants in the survey consider German to be an angry $(45 \%)$, rigid $(31 \%)$, philosophical $(15 \%)$, precise $(6 \%)$ and difficult $(3 \%)$ language. Such value judgments have unavoidable effects on the choice of German as a study subject, on the attitude towards multicultural contact and on the development of nationality-related stereotypes and stigma (Trabant 2008). The idea of the "angry German", in fact, may be considered a legacy of the Second World War and the spread of films and war novels that feature stereotypical bad German soldiers, screaming and giving orders. The description of German as being 
difficult, on the other hand, is most likely due to the linguistic differences, at a typological level, existing between the German and Italian languages (Konig \& Gast 2009). The perception of German as being "philosophical" (prevalent in the students' answers) may be interpreted by taking into account that philosophy is a subject of study in several Italian school programs. In fact, the respondents who gave this definition of the German language hold a tertiary education diploma, so philosophy was a significant part of their curriculum (Beutner \& Pechuel 2017).

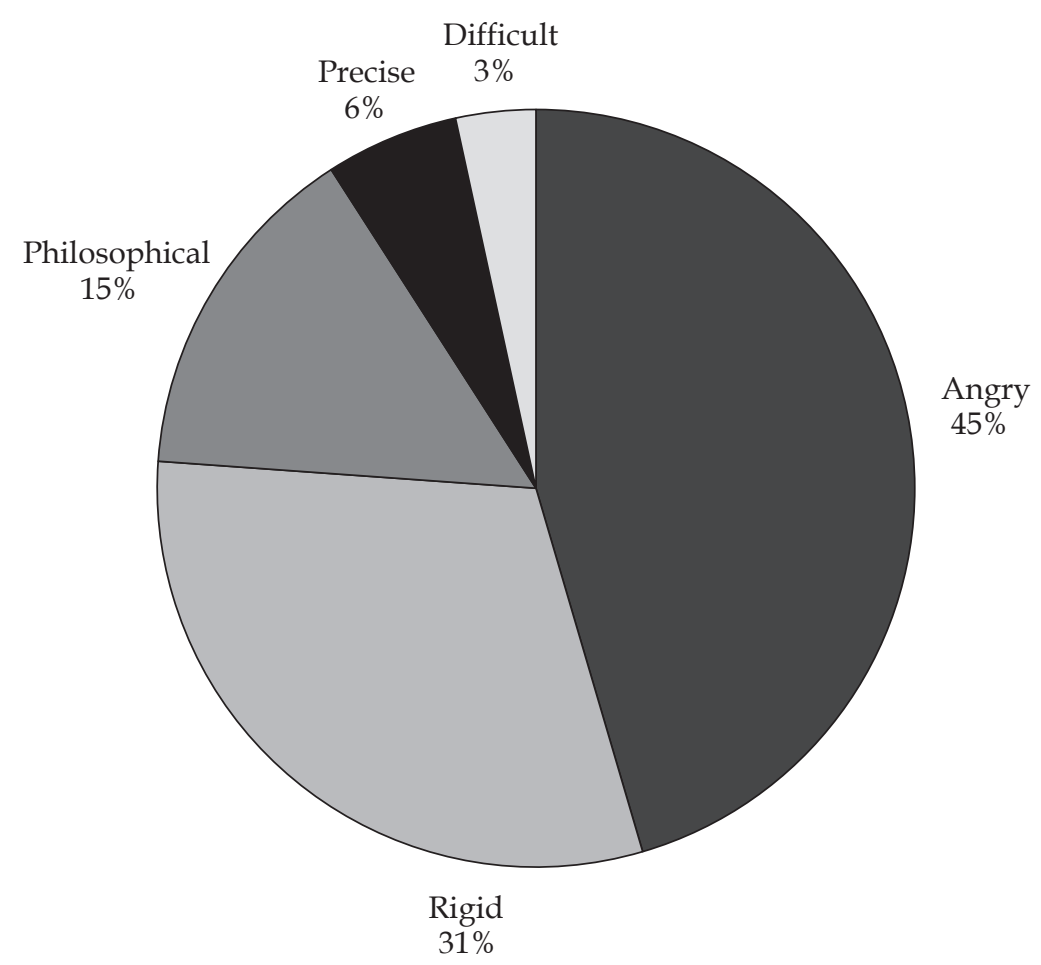

Figure 3. Perception of the German language

With regard to the perception of the Chinese language, it is worth noting that the conglomerate of Sinic languages, commonly labeled as "Chinese", are regarded as ancient $(39 \%)$, difficult $(23 \%)$, philosophical (22\%) and incomprehensible (16\%). These adjectives may reflect the existing preconceptions that arise in the case of languages with fundamentally different writing systems (Sampson 1985) and the communis opinio about Chinese philosophy and culture. 


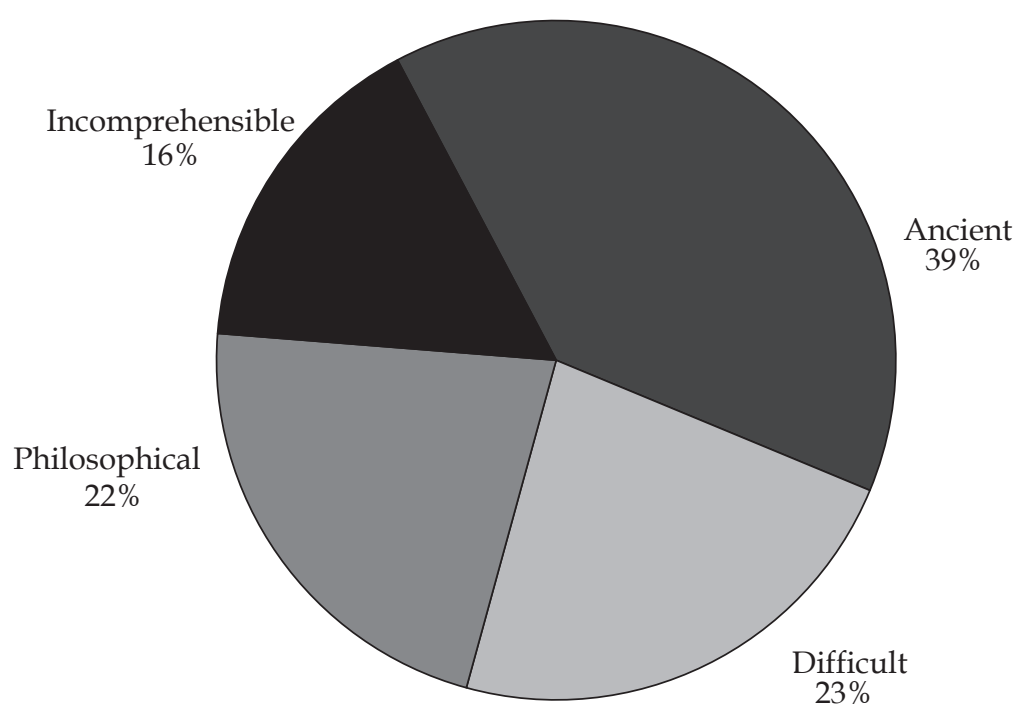

Figure 4. Perception of the Chinese language

With regard to the Russian language, different opinions are reported. In fact, the respondents regard it as controversial (33\%), angry (32\%), difficult to learn $(24 \%)$ and artistic (11\%). Again, languages that feature an alphabet that is different to the Latin seem to cause perceptional difficulty. Furthermore, examining the first two adjectives above, it is interesting to bear in mind that war and spy films set in Russia, or with Russian characters, have always been popular in Italy.

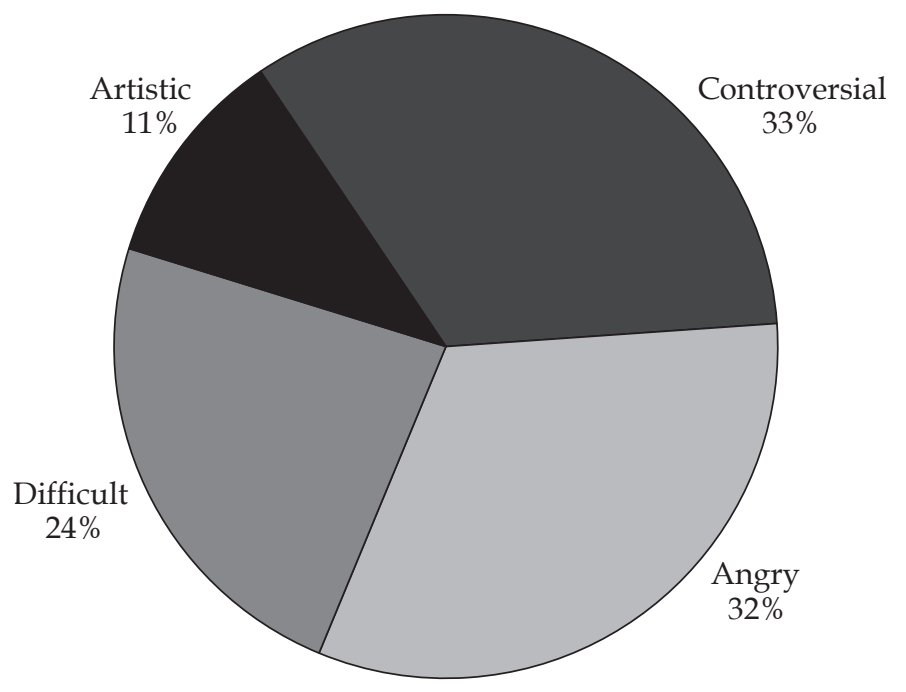

Figure 5. Perception of the Russian language 
Similarly to German, the perception of the French language is very homogenous among all of the questionnaire respondents. Almost $87 \%$ define French as being "romantic", whereas $12 \%$ see it as an artistic language. The most plausible interpretation of these data may be made by taking into account the cultural debt of the Italian artistic and literary traditions to the French, dating back to the Romantic period. The stereotypical Paris, ville d'amour, thus, represents both the symbol of the French as a dominant language and culture and the embodiment of the related preconception at the cultural level (Williams, Burden \& Lanvers 2002).

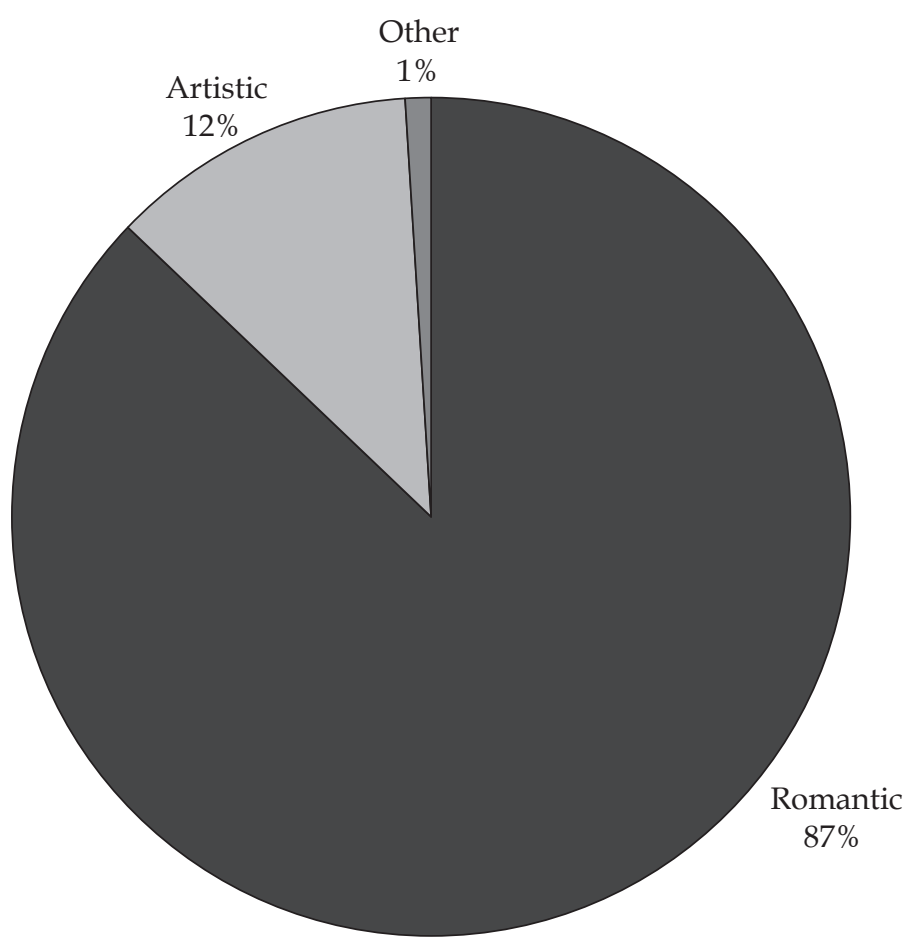

Figure 6. Perception of the French language

The perception of the Spanish language is also fairly uniform among all the questionnaire respondents. In fact, $70 \%$ of the sample define it as a passionate language, while $25 \%$ claim they could learn it easily. These two significant results can be interpreted in terms of the typological proximity of the Spanish and Italian language (Face \& D'Imperio 2005). Indeed, there are several references in Italian cultural history that present love and passion as elements of the Spanish tradition (Barrón 1999). 


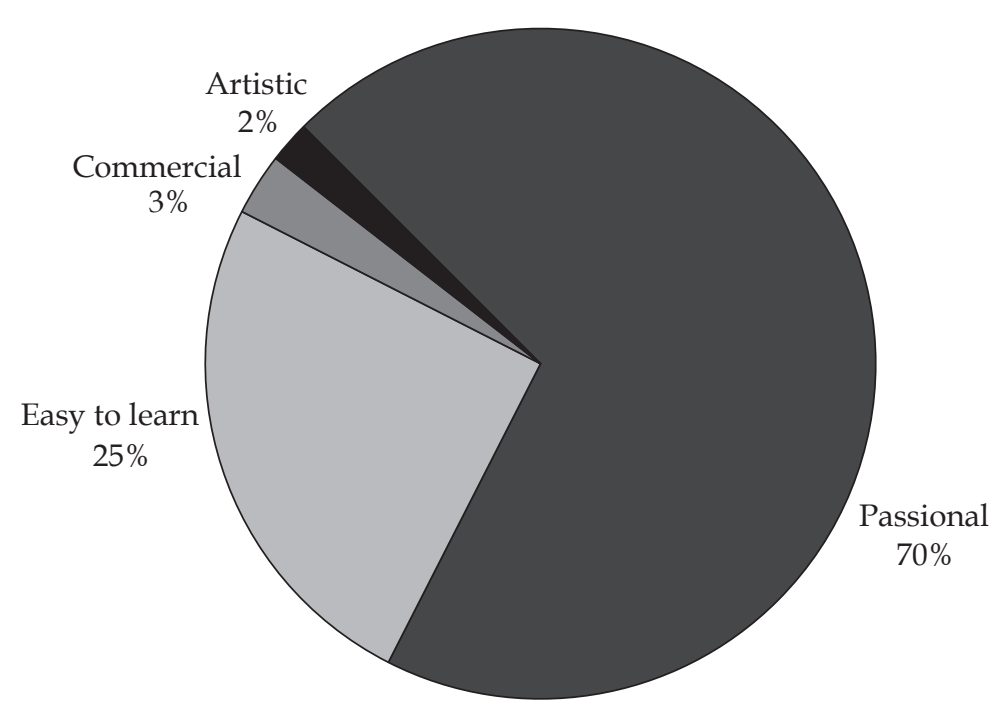

Figure 7. Perception of the Spanish language

The perception of the Arabic language by Italian speakers has some highly significant implications. Our respondents regard Arabic as complicated (41\%), ancient (21\%), mysterious (20\%) and nonsensical (18\%). The feeling of meaninglessness and mystery associated with Arabic is tightly related to the perception of this language as being complicated and ancient; in fact, it is considerably different from Italian in terms of its linguistic typology (Bickford 1998).

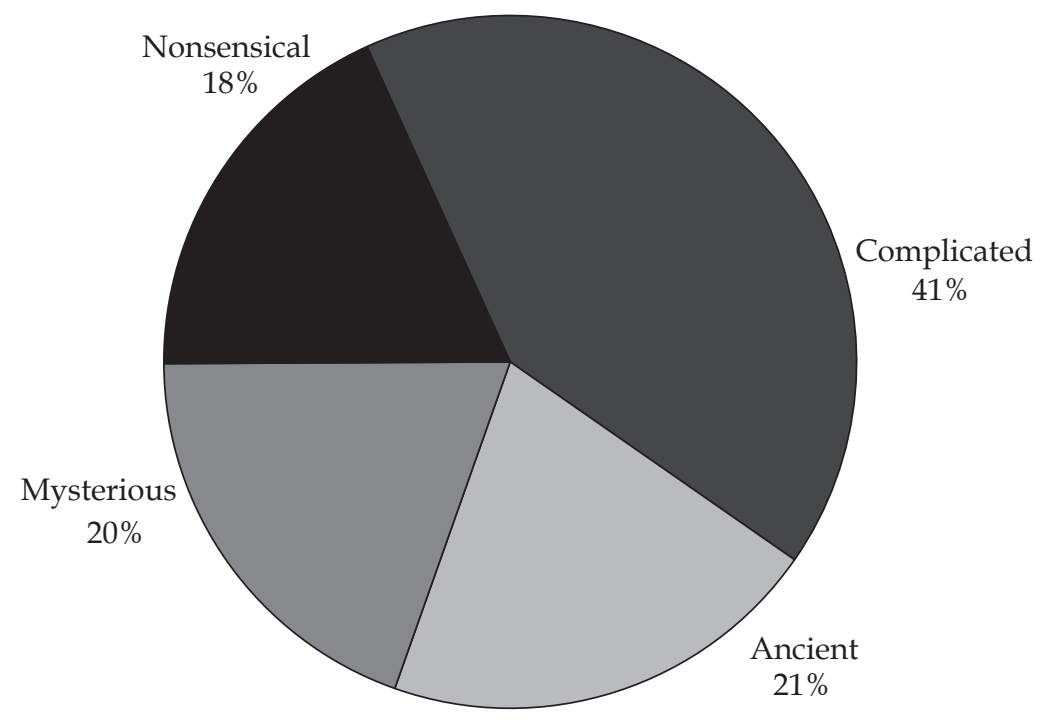

Figure 8. Perception of the Arabic language 


\section{CONCLUSIONS}

This contribution has provided a selection of value judgments regarding selected languages, as collected from a sample of native Italian speakers. The data analysis enabled us to ascertain that the perception of languages is independent of prosodic features but is, on the other hand, strongly affected by cultural preconceptions ( $\mathrm{O}^{\prime}$ Callaghan 2010). Our research clearly demonstrates that the languages that are typologically closer to Italian, in terms of genetic relationship, tend to be associated with positive value judgments, whereas more "distant" ones are perceived with greater suspicion and detachment (Stevens 2002). The examination of such preconceptions is useful for identifying the effects of linguistic contact vs. cultural prestige and, from a linguistic-educational standpoint (Vedovelli 2003). It also constitutes the key to understanding the different choices made when selecting foreign languages to be studied at school: "The education of children develops through language; in learning the language (or languages) of their community, they gradually acquire organizational criteria, as well as the rules of behavior, acting and thinking" (Cardona 2006: 3).

The aim of this essay is not to offer suggestions to counteract prejudice since the research is essentially aimed at exploring and detecting the most frequent preconceptions regarding language. The aim is therefore to demonstrate these trends within the Italian context and to identify the main implications for language teaching (Schneider 2004). Learners "are bound to come across stereotypes (a) for the simple reason that they are part of the lexical inventory of the language they are learning, and (b) teachers do not have control over the input their students get exposed to" (Popovic 2004: 9). Therefore, the choice of foreign languages in the Italian school curriculum (apart from English which is compulsory in almost all training courses), is determined by cultural and economic reasons (Warschauer 2000) and, in part, precisely by the perception of diverse languages.

Teachers can intervene, with the aim of challenging these perceptions, only up to a certain point, since the communis opinio can only be changed within limits (Kramsch 1993). However, teachers should ideally be able to work on raising the awareness of language choices, in relation to a broader intercultural competence (Byram \& Kramsch 2008). As a matter of fact, in educational linguistics, the perception of modern foreign languages plays a fundamental role in the choice of the languages included in curricula (Brumfit 2001) because "the environment in which teaching takes place can also impact the learning process in general, and the learner's attitude in particular. As for stereotypes, there are several dimensions to the learning situation that have to be taken into account, 
the main being the nature of the learner's contact with $\mathrm{L} 2$ native speakers and culture" (Popovic 2004: 8).

One course of action to combat the stereotypes associated with foreign languages and cultures is to work on intercultural communication, by facilitating the understanding of the role of foreign languages in the Italian-speaking context because "the prejudice literature has largely overlooked the role of intercultural communication in determining people's evaluative orientation toward ethnolinguistic outgroups. Intercultural communication emotions (negative affect associated with perceived linguistic and cultural barriers) were investigated as determinants of prejudice, in conjunction with causal factors that are widely recognized as central to intergroup judgments" (Spencer-Rodgers \& Mcgovern 2002: 609). Our research results, therefore, implicitly move towards an intercultural perspective, "contributing to the fulfillment of (sometimes seemingly abstract) curricular aims that emphasize the significance of intercultural communication, awareness of cultural variety, and intercultural sensitivity" (Stopar 2015: 105).

Further research could take into consideration a larger sample, including different informant profiles, and the exploration of linguistic-educational strategies in order to address prejudices and stereotypes (Deutscher 2011). This could include a more in-depth examination of the implications of stereotypes (Hilton \& Von Hippel 1996), both on an educational and communicative level and from a sociological point of view, because "cultural value orientations drive language usage in everyday lives. [...] World-view refers to our larger philosophical outlook or ways of perceiving the world and how this outlook, in turn, affects our thinking and reasoning patterns" (Ting-Toomey \& Chung 2012: 118-119).

The survey study undertaken by the present authors, therefore, has allowed assessing the presence of stereotypes, which can undoubtedly be attributed to the relationships between cultures and speakers (Hay \& Drager 2010). The research presented is not free from criticalities, which are mainly due to the limited number of questionnaire respondents. A more numerous sample could certainly lead to more robust results. Another important factor to consider is the need for a mixed-methods study, incorporating methods originating in the fields of sociology and anthropology.

\section{REFERENCES}

Barrón, A. / Martínez-Iñigo, D. / De Paul, P. / Yela, C. (1999). Romantic beliefs and myths in Spain.

The Spanish Journal of Psychology, 2 (1), 64-73. DOI: 10.1017/S1138741600005461.

Bazzanella, C. (2019). Linguistica cognitiva. Roma-Bari: Editori Laterza.

Berruto, G. (2015). Manuale di sociolinguistica. Novara: UTET. 
Berruto, G. (2020). Prima lezione di sociolinguistica. Roma-Bari: Editori Laterza.

Beutner, M. / Pechuel, R. (2017). Education and educational policy in Germany. A focus on core developments since 1944. Italian Journal of Sociology of Education, 9 (2), 9-24. http:/ /ijse.padovauniversitypress.it/2017/2/2 [access: 29.01.2021].

Bickford, J.A. (1998). Tools for analyzing the world's languages: Morphology and syntax. Dallas: Summer Institute of Linguistics.

Björkman, B. (2011). English as a lingua franca in higher education: Implications for EAP. Ibérica, $22,79-100$.

Blommaert, J. (2012). The sociolinguistics of globalization. Cambridge: Cambridge University Press. DOI: 10.1017/CBO9780511845307.

Brumfit, C. (2001). Individual freedom in language teaching: Helping learners to develop a dialect of their own. Oxford: Oxford University Press. DOI: 10.1017/S0272263103230187.

Burani, C. / Laudanna, A. (1993). Il lessico: processi e rappresentazioni. Roma: Carocci editore.

Byram, K. / Kramsch, C. (2008). Why is it so difficult to teach language as culture? The German Quarterly, 81 (1), 20-34.

Cardona, G.R. (2006). Introduzione all'etnolinguistica. Novara: UTET.

Cooper, J. / Fazio, R.H. (1984). A new look at dissonance theory. Advances in Experimental Social Psychology, 17 (C), 229-266. DOI: 10.1016/S0065-2601(08)60121-5.

De Kock, L. (2014). Hermann von Helmholtz's empirico-transcendentalism reconsidered: Construction and constitution in Helmholtz's psychology of the object. Science in Context, 27, 709-744. DOI: $10.1017 /$ S026988971400026X.

De Martino, D. / Maraschio, N. (eds.) (2013). Fuori l'italiano dall'università? Inglese, internazionalizzazione, politica linguistica. Roma-Bari: Editori Laterza.

Dervin, F. / Gajardo, A. / Lavanchy, A. (eds.) (2012). Politics of interculturality. Newcastle: Cambridge Scholars.

Deutscher, G. (2011). Through the language glass: Why the world looks different in other languages. London: Arrow Books.

Dietz, G. (2009). Multiculturalism, interculturality and diversity in education: An anthropological approach. Münster: Waxmann.

Elman, J.L. / McClelland, J.L. (1986). The TRACE model of speech perception. Cognitive Psychology, 18 (1), 1-86. DOI: 10.1016/0010-0285(86)90015-0.

Face, T. / D'Imperio, M. (2005). Reconsidering a focal typology: Evidence from Spanish and Italian. Italian Journal of Linguistics, 17, 271-289.

Garrett, P. (2012). Attitudes to language. Cambridge: Cambridge University Press. DOI: 10.1017/ CBO9780511844713.

Hay, J. / Drager, K. (2010). Stuffed toys and speech perception. Linguistics, 48 (4), 865-892. DOI: 10.1515/LING.2010.027.

Hilton, J.L. / Von Hippel, W. (1996). Stereotypes. Annual Review of Psychology, 47 (1), 237-71.

Hudson, R. (1996). Sociolinguistics. Cambridge: Cambridge University Press. DOI: 10.1017/ CBO9781139166843.

Hynninen, N. (2011). The practice of 'mediation' in English as a lingua franca interaction. Journal of Pragmatics, 43, 965-977. DOI: 10.1016/j.pragma.2010.07.034.

Kanizsa, G. (1980). La grammatica del vedere. Bologna: Il Mulino.

Konig, E. / Gast, V. (2009). Understanding English-German contrasts. Berlin: Erich Schmidt Verlag.

Kramsch, C. (1993). Context and culture in language teaching. Oxford: Oxford University Press.

Loewen, S. / Plonsky, L. (2016). An A-Z of applied linguistics research methods. London-New York: Palgrave Macmillan. 
Marello, C. (1999). Riflettere sulla lingua. Firenze: La Nuova Italia.

Neisser, U. (1993). The perceived self: Ecological and interpersonal sources of self-knowledge. Cambridge: Cambridge University Press.

Nitti, P. (2018a). Didattica della lingua italiana per gruppi disomogenei. Brescia: Editrice La Scuola.

Nitti, P. (2018b). La costruzione di un questionario sociolinguistico. Scuola e Didattica, 4, 34-36.

Nitti, P. (2019). Didattica dell'italiano L2. Dall'alfabetizzazione allo sviluppo della competenza testuale. Brescia: Editrice La Scuola.

Nitti, P. (2020). L'alfabetizzazione in italiano L2 per apprendenti adulti non nativi. Milano / Udine: Mimesis. O'Callaghan, C. (2010). Experiencing speech. Philosophical Issues, 20, 305-327.

Ostler, N. (2005). Empires of the world. A language history of the world. New York: HarperCollins.

Patel, A. (2008). Music, language and brain. New York: Oxford University Press.

Popovic, R. (2004). National stereotypes in teaching English as a foreign language. MA TESOL Collection, 142, 1-118.

Rapallo, U. (1994). La ricerca in linguistica. Roma: Carocci editore.

Sampson, G. (1985). Writing systems: A linguistic introduction. Stanford, CA: Stanford University Press.

Schiffrin, D. (1993). "Speaking for another" in sociolinguistic interviews: Alignments, identities, and frames. In: D. Tannen (ed.), Framing in discourse (pp. 231-263). New York: Oxford University Press. DOI: 10.1016/j.pragma.2007.03.005.

Schneider, D.J. (2004). The psychology of stereotyping. New York: Guilford Press.

Seidlholfer, B. (2011). Understanding English as a lingua franca. Oxford: Oxford University Press.

Spencer-Rodgers, J. / McGovern, T. (2002). Attitudes toward the culturally different: The role of intercultural communication barriers, affective responses, consensual stereotypes, and perceived threat. International Journal of Intercultural Relations, 26, 609-631. DOI: 10.1016/ S0147-1767(02)00038-X.

Stevens, K.N. (2002). Toward a model of lexical access based on acoustic landmarks and distinctive features. Journal of the Acoustical Society of America, 111 (4), 1872-1891. DOI: 10.1121/1.1458026.

Stopar, A. (2015). Encounters with national stereotypes in foreign language teaching: Adjectives describing Americans. ELOPE: English Language Overseas Perspectives and Enquiries, 12 (1), 105-118. DOI: 10.4312/elope.12.1.105-118.

Tagliamonte, S. (2006). Analysing sociolinguistic variation. Cambridge: CUP. DOI: 10.1017/ CBO9780511801624.

Telmon, T. (1990). Guida allo studio degli italiani regionali. Alessandria: Edizioni dell'Orso.

Ting-Toomey, S. / Chung, L.C. (2012). Understanding intercultural communication. New York: Oxford University Press.

Tolbert, E. (2001). Music and meaning. An evolutionary story. Psychology of Music, 29, 89-94. DOI: $10.1177 / 0305735601291007$.

Trabant, J. (2008). Was ist Sprache? München: Beck.

Turner, S. (1994). In the eye's mind. Vision and the Helmholtz-Hering controversy. Princeton: Princeton University Press.

Underhill, J.W. (2012). Ethnolinguistics and cultural concepts: Love, truth, hate $\mathcal{E}$ war. Cambridge: Cambridge University Press.

Vedovelli, M. (2003). Note sulla glottodidattica italiana oggi: problemi e prospettive. Studi Italiani di Linguistica Teorica e Applicata, 32, 173-197.

Volli, U. (2003). Manuale di semiotica. Roma: Editori Laterza.

Wardhaugh, R. (2006). An introduction to sociolinguistics. New York: Wiley-Blackwell.

Warschauer, M. (2000). The changing global economy and the future of English teaching. TESOL Quarterly, 34 (3), 511-535. DOI: 10.2307/3587741. 
Wierzbicka, A. (1999). Emotions across languages and cultures. Cambridge: Cambridge University Press. DOI: 10.1017/CBO9780511521256.

Williams, M. / Burden, R. / Lanvers, U. (2002). 'French is the language of love and stuff': Student perceptions of issues related to motivation in learning a foreign language. British Educational Research Journal, 28 (4), 503-528. DOI: 10.1080/0141192022000005805.

Yule, G. (2020). Language and culture. In the study of language. Cambridge: Cambridge University Press. DOI: 10.1017/CBO9780511757754.

Received: 20.04.2020; revised: 04.02.2021

\section{PAOLO NITTI}

Università degli Studi dell'Insubria

paolo.nitti@uninsubria.it

ORCID: orcid.org/0000-0003-1263-7482

\section{GIULIO FACCHETTI}

Università degli Studi dell'Insubria

giulio.facchetti@uninsubria.it

ORCID: orcid.org/0000-0001-9532-673X 